\title{
Cost-effectiveness of teriparatide compared with alendronate and risedronate for the treatment of postmenopausal osteoporosis patients in Iran
}

\author{
Amir Ali Ebadi Fard Azar ${ }^{1}$, Aziz Rezapour², Vahid Alipour², Ali Sarabi-Asiabar², Serajaddin Gray ${ }^{3}$ \\ Mohammadreza Mobinizadeh ${ }^{4}$, Mani Yousefvand ${ }^{3}$, Jalal Arabloo ${ }^{2 *}$
}

Received: 10 Jan 2017

Published: 18 July 2017

\section{Abstract}

Background: Hip, vertebral and wrist fractures are the most common consequences of osteoporosis. This study aimed at analyzing the cost-effectiveness of teriparatide (CinnoPar $\left.{ }^{\circledR}\right)$, compared with alendronate and risedronate, in the treatment of women aged 60 and over with postmenopausal osteoporosis in Iran.

Methods: A decision tree model with a 2-year time horizon was used to compare treatment with teriparatide $\left(\operatorname{CinnoPar}{ }^{\circledR}\right)$ with the following treatment strategies: two years of treatment with alendronate and two years of treatment with risedronate in women aged 60 years and over or those at risk of osteoporosis. Cost per QALY was calculated for 3 treatment strategies from the model. After base case analysis, one-way sensitivity analysis was performed on key parameters of the model to assess their impact on the study results and the cost-effectiveness of different treatment strategies and the model robustness. TreeAge Pro 2011 software was used for modeling and data analysis.

Results: Incremental cost-effectiveness ratio (ICER) of alendronate and teriparatide than risedronate (base treatment) were US\$2178.03 and US\$483,783.67 per QALY, respectively. Therefore, the dominant and cost-effective treatment option was alendronate. In the one-way sensitivity analysis, the impact of annual $25 \%$ increase or decrease in the teriparatide cost on its ICER was remarkable. Also, reducing the discount rate from 0.03 to 0.0 had the greatest impact on the ICER of the teriparatide.

Conclusion: The treatment strategy of teriparatide is more expensive than risedronate and alendronate and is associated with very little increase in QALYs. A significant reduction in teriparatide price and a limit in its use only for high-risk women and for acute and short-term treatment courses can contribute to its cost-effectiveness.

Keywords: Osteoporosis, Cost-effectiveness, Teriparatide, Risedronate, Alendronate, Postmenopausal Women, Fracture, Iran

Copyright $\odot$ Iran University of Medical Sciences

Cite this article as: Ebadi Fard Azar AA, Rezapour A, Alipour V, Sarabi-Asiabar A, Gray S, Mobinizadeh6 M, Yousefvand M, Arabloo J. Costeffectiveness of teriparatide compared with alendronate and risedronate for the treatment of postmenopausal osteoporosis patients in Iran. Med $J$ Islam Repub Iran. 2017 (18 July);31:39. https://doi.org/10.14196/mjiri.31.39

\section{Introduction}

Osteoporosis is a systemic skeletal disease characterized by low bone mass and the deterioration of bone tissue and increases the risk of fractures, especially hip, vertebrae, and wrist $(1,2)$. Osteoporosis has become a serious health problem, especially among the elderly, and it was recognized as a serious public health problem, with about 200 million people being affected worldwide in 2012 (3). A

Corresponding author: Dr Jalal Arabloo, arabloo_j64@yahoo.com

1. Medicine School, Iran University of Medical Sciences, Tehran, Iran.

2. Health Management and Economics Research Center, Iran University of Medical Sciences, Tehran, Iran.

3. Department of Health Management and Economics, School of Public Health, Tehran University of Medical Sciences, Tehran, Iran.

4. National Institute for Health Research, Tehran University of Medical Sciences, Tehran, Iran. total of about 5.5 million people suffered from osteoporosis in Europe in 2012 (4). Different figures have been reported among Iranian women for the prevalence of the disease $(6 \%$ to $43 \%)(5)$. Osteoporosis-associated fractures impose a high economic and social burd en on the society, owing to its impact on the mortality and quality of life (6). For example, in Sweden, hip fracture accounts for

$\uparrow$ What is "already known" in this topic:

There are no results about the cost-effectiveness of teriparatide compared with alendronate and risedronate for treatment of patients with postmenopausal osteoporosis in Iran.

\section{$\rightarrow$ What this article adds:}

The treatment strategy of teriparatide is more expensive than risedronate and alendronate and is associated with very little increase in QALYs in Iran. 
$1.5 \%$ of the annual total mortality rate and a reduction of approximately 1000 years of life (7). In 2005, more than 2 million Americans suffered from osteoporosis-associated fractures, the economic costs of which have been estimated to be US\$17 billion (8).

In general, osteoporosis, which is defined with a Tscore (bone mass measurement test) of about -2.5 and lower, affects most postmenopausal women. Age, gender, low body weight, race, lack of vitamin $\mathrm{D}$, and underlying medical conditions are among important factors involving the loss of bone mass (9). Women's gender and menopause have been reported as osteoporosis risk factors in Iran (10).

Due to the multifactorial nature of osteoporosis, its prevention, and management is particularly complex. All medical interventions aim to maintain bone mass, skeleton structural integrity, and avoid brittle bones from the prevention stage to the treatment stage of the disease (9). Clinical studies have shown that non-medicine treatments together with medicine treatments such as vitamin D, calcium, bisphosphonates (such as alendronate and risedronate) as well as selective estrogen receptor modulators (SERMs) reduce the fracture rate $(6,11)$. Teriparatide is also used as a recombinant human hormone or rhPTH (1-34) to increase bone mineral density (BMD) and reduce the fracture risk (12-14).

Bisphosphonates were used to prevent and treat osteoporosis since the introduction of alendronate in 1995(11, 15). Bisphosphonates is considered popular and effective for the treatment of osteoporosis because of its effectiveness and long-term effects, however, its cost-effectiveness has not been approved in contrast with new medicines such as denosumab (15-17). Teriparatide (recombinant human hormone) is one of the first anabolic osteoporosis drugs, which was approved by the Food and Drug Administration (FDA) in 2002(13). This medicine can be an appropriate treatment for osteoporosis caused by glucocorti- coids, and its daily consumption stimulates bone formation and increases the bone mass. Thereby, it decreases the risk of spine fracture and other bones (14). In a study on postmenopausal women with glucocorticoid-induced osteoporosis, treatment with synthetic teriparatide and estrogen, compared with the estrogen alone, significantly increased the mineral density of lumbar spine bone (18). Also, based on a cost-effectiveness study, the drug was a cost-effective option compared with a non-treatment option (19).

Considering the fact that osteoporosis is considered a serious health problem in developing countries and its impact on the mortality, the quality of life, and the increasing costs of health systems, it is essential to determine the cost-effectiveness of drugs used to prevent and treat the disease; thus, policymakers should optimally allocate resources and make appropriate decisions in this regard $(4,6)$. The current study aimed at analyzing the cost-effectiveness of risedronate, alendronate, and teriparatide $\left(\right.$ CinnoPar $\left.^{\circledR}\right)$ in treatment of osteoporosis in Iranian postmenopausal women aged 60 years and over.

\section{Methods}

Teriparatide (with brand name of CinnoPar ${ }^{\circledR}$ ) costeffectiveness analysis, compared with alendronate and risedronate, was performed in the form of a decision tree model and considering 3 different health states (hip, spine, and wrist fractures) to compare treatment strategies. The initial model, which was extracted from Liu et al. (13), was localized for the country's economic conditions, experts, and clinicians' opinions, available information as well as clinical guidelines (Fig. 1). The results of the decision tree model were obtained in incremental costeffectiveness ratios (ICERs) for the 3 treatment strategies as cost per QALY.

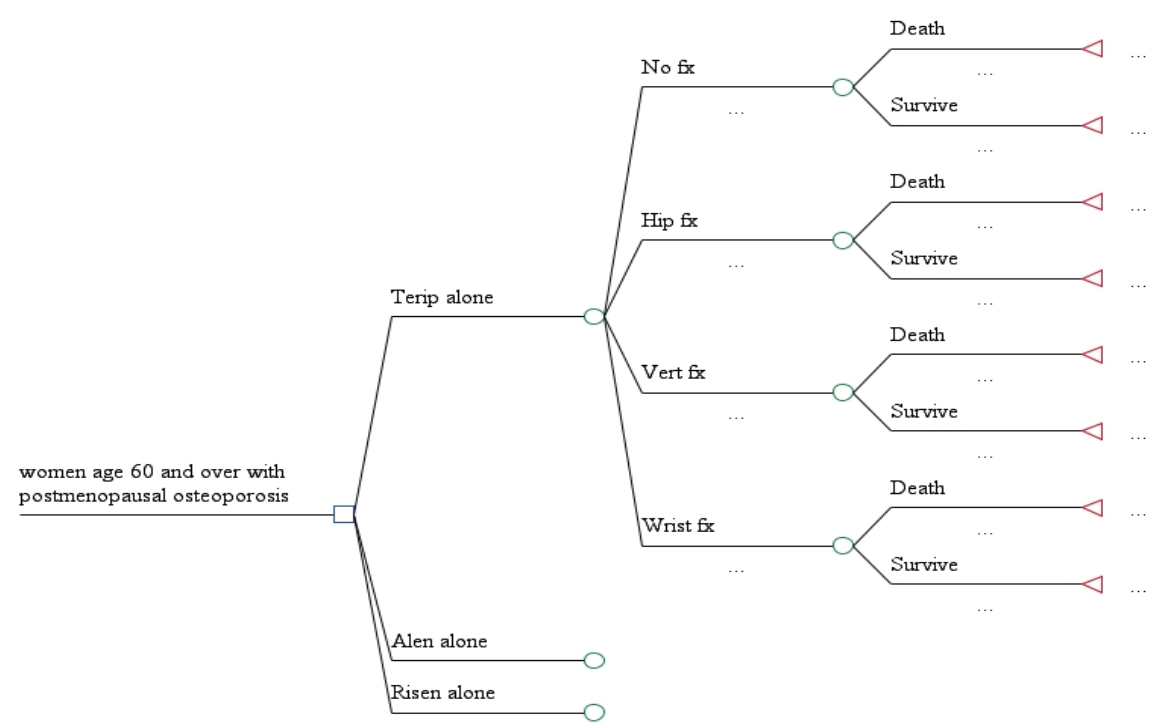

Abbreviations: alendronate (Alen); teriparatide (Terip); risedronate (Risen) vertebral (Vert); fracture (Fx)

Fig. 1. Schematic Structure of the Decision Tree Model (A Modified Version of Liu et al., 2006) 


\section{Analytical Model}

The microsimulation was performed for 1000 hypothetical population in the modified model of Liu et al. (13). TreeAge Pro 2011 (Tree- Age Software Inc. Williamstown, MA, USA) was used for modeling and data analysis. The model key components are as follow: selected treatment strategies for the osteoporosis treatment, health events in decision tree arms (no fracture, hip fracture, wrist fracture, vertebral fracture, death, and survival), and the probabilities. The time horizon of 2 years was considered in this study and costs were analyzed from the health system perspective. Costs and utilities were discounted at a rate of $3 \%$. To calculate the willingness-to-pay threshold, the World Health Organization's approach was used, that is, if the ICER ratio was less than 3 times the country's per capita gross domestic product (GDP), the treatment option would be considered as a cost-effective strategy, whereas one that costs less than once the national annual GDP per capita was considered highly costeffective (20). Taking into account Iran's per capita GDP of US\$4670 in 2014(21), the willingness-to-pay threshold was considered to be US\$14010.

\section{Population}

Due to the high prevalence of osteoporosis at the age of 60 years and over in Iran, the studied population was selected from patients aged 60 years and over. Therefore, postmenopausal women older than 60 years with the Tscore of -2.5 or lower, and with at least a history of spine, wrist, and hip fracture caused by osteoporotic, were investigated as the target population in this study. Cost data of 1150 patients of 60 years and older who were admitted to the hospitals in due to osteoporotic hip, vertebral, and wrist fractures were used in the model.

\section{Therapeutic Strategies}

In this study, the cost-effectiveness analysis of 3 treatment strategies for the osteoporosis treatment was assessed as follows:

- Two years of treatment using teriparatide $\left(\right.$ CinnoPar $\left.{ }^{\circledR}\right)$ at a dose of $20 \mu \mathrm{g} /$ day subcutaneously

- Two years of treatment using alendronate at a dose of $70 \mathrm{mg} /$ week

- Two years of treatment using risedronate at a dose of 5 $\mathrm{mg} /$ day

\section{Transition Probabilities}

In this study, the risk of hip, wrist, and spine fractures in postmenopausal women was obtained for each of the treatment strategies based on data of the published studies and by multiplying the relative risk fractures of hip, spine, and wrist by the fracture rate of the control group (22-24). Also, the risk of death due to the hip fracture was determined to be 0.0025 according to U.S. Congress, Office of Technology Assessment (25) and by taking the average of the chance for age groups of 60 to 99 years (Table 1 ).

\section{Costs and Discounting}

Costs were studied from the health system perspective. Thus, the direct medical costs including the cost of medicines and hospitalization were entered into the study. According to the 2-year time horizon in the study, the direct medical costs related to 3 types of fractures (i.e., hip, vertebral, and wrist fractures) were measured by investigating

\begin{tabular}{|c|c|c|c|}
\hline & Parameters & Input value & Reference \\
\hline \multirow[t]{3}{*}{ Per annum drug costs (US\$) } & Alendronate & 9 & calculated \\
\hline & risedronate & 6.5 & calculated \\
\hline & Teriparatide (CinnoPar $\left.{ }^{\circledR}\right)$ & 1,627 & calculated \\
\hline \multirow{6}{*}{$\begin{array}{l}\text { Hospitalization costs, per } \\
\text { event } \\
\text { (US\$) }\end{array}$} & Hip fracture, first year & 1,845 & calculated \\
\hline & Hip fracture, second year & 2,452 & calculated \\
\hline & Vertebral fracture, first year & 3,404 & calculated \\
\hline & Vertebral fracture, second year & 3,259 & calculated \\
\hline & Wrist fracture, first year & 1,034 & calculated \\
\hline & Wrist fracture, second year & 1,323 & calculated \\
\hline \multirow[t]{7}{*}{ Quality-of-life utilities } & Utility for patients who experience one Hip fracture, first year & 0.797 & 13 \\
\hline & Utility for patients who experience one Hip fracture, second year & 0.90 & 13 \\
\hline & Utility for patients who experience one Vertebral fracture, first year & 0.82 & 13 \\
\hline & Utility for patients who experience one Vertebral fracture, second year & 0.931 & 13 \\
\hline & Utility for patients who experience one Wrist fracture, first year & 0.981 & 13 \\
\hline & Utility for patients who experience one Wrist fracture, second year & 1 & 13 \\
\hline & Death & 0 & 13 \\
\hline \multirow{12}{*}{$\begin{array}{l}\text { Relative risks for the use of } \\
\text { drugs }\end{array}$} & Alone alendronate strategy & & \\
\hline & Vertebral & 0.48 & 22 \\
\hline & Hip & 0.61 & 22 \\
\hline & Wrist & 0.61 & 22 \\
\hline & Alone risedronate strategy & & \\
\hline & Vertebral & 0.53 & 20 \\
\hline & Hip & 0.49 & 20 \\
\hline & Wrist & 0.53 & 20 \\
\hline & Alone teriparatide strategy & & \\
\hline & Vertebral & 0.35 & 21 \\
\hline & Hip & 0.47 & 21 \\
\hline & Wrist & 0.47 & 21 \\
\hline \multirow[t]{2}{*}{ Discount Rate } & Costs & 0.03 & assumed \\
\hline & QALYs & 0.03 & assumed \\
\hline
\end{tabular}


the records of 1150 osteoporotic patients who suffered from wrist, hip, and vertebral fractures and were hospitalized in hospitals across the country. The costs of hospitalization were calculated through electronic health records system (EHRS) of the Ministry of Health during 2014 and 2015 (Table 1). Also, the costs of drugs were calculated using the drug price list of Food and Drug Administration and based on the average wholesale price of teriparatide $\left(\right.$ CinnoPar $\left.^{\circledR}\right)$, different brands of alendronate and risedronate (the price of domestically produced drugs was considered) as well as by taking into account the patient's daily dose. One-way sensitivity analysis was performed for the acceptable range of these costs due to the differences in the prices of medicines and medical services tariffs, and all costs were converted to 2014 USD. According to the Central Bank of Iran, the United States dollar was 30350 I.R Rials. According to exchange rate in 2014, the United States dollar was 30350 I.R Rials.

\section{Health State Utilities}

In this study, studies published in this area were used to extract the different states of health utilities (13). In these studies, the utilities were calculated using standard gamble and time trade-off methods. The values of utilities were different for wrist, hip, and spine fractures for the first and second years, and the utility for the death state was considered zero (Table 1).

\section{Sensitivity Analysis}

The model robustness and its results were evaluated using one-way sensitivity analysis. According to health evo- lution plan and annual change in tariffs for public inpatient services and physician visits as well as based on experts' opinions, costs were considered as the most important parameters affecting the analysis results. One-way sensitivity analysis was performed for the costs of drugs and fractures of the wrist, hip, and spine, with a rate of $\pm 25 \%$ and $\pm 30 \%$, respectively.

\section{Results}

\section{Base-Case Analysis}

Based on the base case analysis, incremental cost effectiveness ratio (ICER) of alendronate and teriparatide than risedronate (base treatment) was US\$-2178.03 and US\$483783.67 per QALY, respectively. Therefore, alendronate found to be the dominant and cost-effective treatment option.

Also, the results of the incremental cost-effectiveness ratio of teriparatide and alendronate strategies, compared to risedronate (base-case $=$ risedronate), revealed that alendronate had a lower cost and more QALY.

Although teriparatide had more QALY compared with risedronate treatment (base), it was more costly at as well.

Thus, alendronate was the dominant drug compared with the risedronate, but none of the treatment options was considered as the dominant option among the treatment strategies (Table 2). Cost-effectiveness plane of the osteoporosis treatment alternatives are demonstrated in Fig. 2.

\section{Sensitivity Analysis}

One-way sensitivity analysis was performed on the annual cost of drugs at a rate of $\pm 25 \%$ (Table 3 ). Based on

Table 2. Costs, Outcomes, and Incremental Cost-effectiveness Estimates (Base $=$ Risedronate)

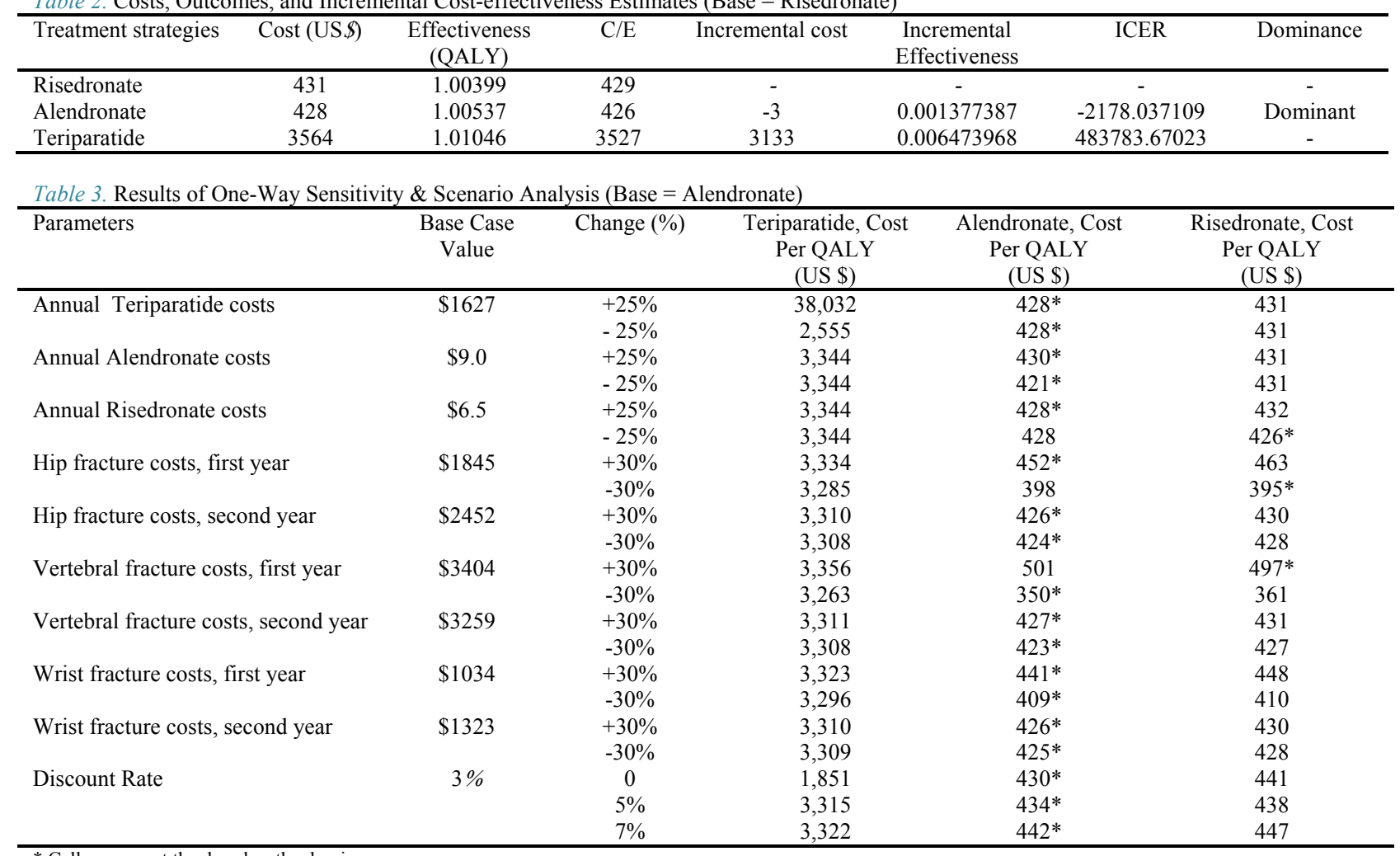

\footnotetext{
* Cells represent the drug has the dominance.
} 


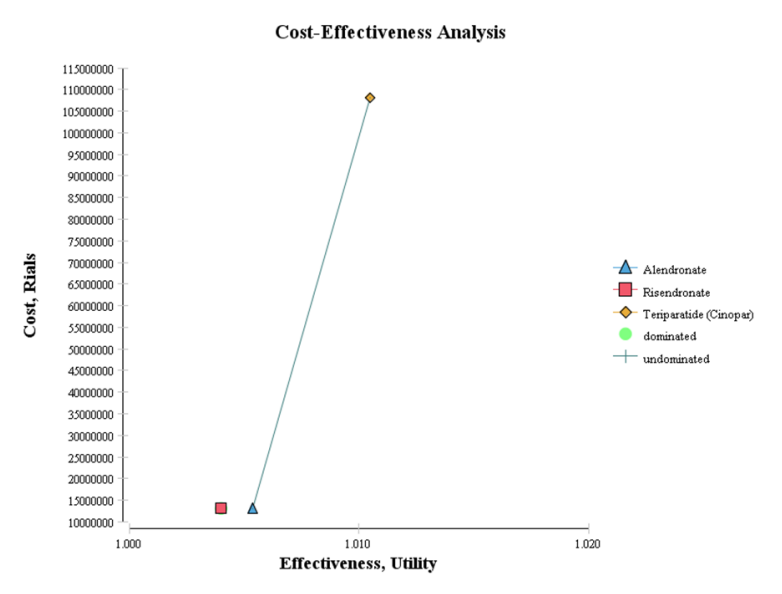

Fig. 2. Cost-effectiveness Plane

the findings, with a $25 \%$ reduction in the annual cost of risedronate, it changed to a cost-effective option compared with the 2 other drugs. However, with the increase and decrease in the annual costs for teriparatide $\left(\mathrm{CinnoPar}^{\mathbb{B}}\right)$ and alendronate, there was no change in the study results. The results of sensitivity analysis on the costs of hip, spine, and wrist fractures at a rate of $\pm 30 \%$ in the first and second year revealed that if the costs of the hip and vertebral fractures are reduced by $30 \%$ in the first year, the study results will change and the risedronate will be selected as the cost-effective treatment option. Increases or decreases in the discount rate did not change the result of the study (Table 3 ).

\section{Discussion}

This study analyzed the costs-effectiveness of teriparatide $\left(\mathrm{CinnoPar}^{\mathbb{R}}\right)$ compared with alendronate and risedronate in the prevention and treatment of osteoporosis in Iranian women aged 60 years and over. In this study, the decision tree model was used for modeling the costs and effects including vertebral, wrist, and hip fracture reduction in one-year cycle and time horizon of 2 years. The cost analysis was considered based on the payer's perspective. Despite the fact that teriparatide is used as a new strategy in the prevention and treatment of osteoporosis, the present study found that the it is less cost- effective, mainly due to its high costs compared with alendronate and risedronate. In fact, although teriparatide has gained a slight increase in QALYs compared with the 2 other strategies, its total costs are about 8 times more than alendronate and risedronate. In this study, alendronate therapy strategy was more cost-effective than other interventions in treating postmenopausal women at risk of osteoporosis. According to the study results, incremental cost- effectiveness ratio (ICER) of alendronate and teriparatide than risedronate (base treatment) was US\$2178.037109 and US\$483 783.67023 per QALY, respectively. Therefore, the dominant and cost-effective treatment option was alendronate. The results of incremental cost-effectiveness revealed that if risedronate is considered as the base option, alendronate will have lower costs and more QALY, and thus will be the dominant option.
The sensitivity analysis showed that the results of the model were sensitive to costs and that reduction of the annual cost of risedronate by $25 \%$, reduction in hip fracture costs in the first year by $30 \%$, and $30 \%$ increase in the cost of spinal fractures in the first year, made risedronate more cost-effective compared with the other 2 strategies. In other cases of the sensitivity analysis, the study results remained unchanged and alendronate continued to be the cost-effective option. Although treatment interventions were not compared with the non-treatment option, most studies showed that osteoporosis interventions were costeffective in women over 60 years with low bone density and previous fracture history, compared with the nontreatment option (26). For example, the results of the previous studies show that teriparatide $(27,28)$, alendronate $(29,30)$, and risedronate $(31,32)$ have been cost- effective compared with no-treatment option. In addition, previous systematic review studies showed that oral bisphosphonates compared with hormonal drugs such as teriparatide are more cost- effective in women over 70 years, particularly those with more risk factors $(6,33)$. For example, the results of a study conducted by National Institute for Health and Clinical Excellence, which evaluated the cost effectiveness of bisphosphonates and teriparatide based on the 2 models of the manufacturer and the Institute's Evaluation Group showed that the incremental costeffectiveness ratio of teriparatide in the manufacturer's model, compared with the comparator (no treatment), was $£ 35400$ per QALY. The same figures were $£ 577$ and $£ 3135$ per QALY for alendronate and risedronate, respectively (34). These results are consistent with findings of Thomson et al. (2010), which found that risedronate has led to less fracture rates (reduction in 12 months), more QALYs and less costs compared with alendronate (35). However, unlike the results of National Institute of Clinical Excellence study, Murphy et al. (27) indicated that the use of teriparatide was a cost-effective option as first-line treatment with incremental cost-effectiveness ratio of $€ 50$ 000 per QALY, compared with both the non- treatment option and bisphosphonate. In contrast, study of Tosteson et al. (36) showed that among no- treatment, risedronate, and alendronate options, ibandronate and teriparatide treatment options were dominant.

In general, by taking into account the differences in the risk of fractures, comparators, countries conditions, the model structure and patients' adherence to the recommended treatment regimens, it is impossible to present clear recommendations about the relative costeffectiveness of interventions used to prevent and treat osteoporosis. Typically, there are a few studies that include all medicine interventions for treatment of osteoporosis. Moreover, due to different methodological approaches, it is less likely to compare studies or characteristics of the study population. Furthermore, the generalizability of the previous studies on the cost- effectiveness of osteoporosis drugs are associated with uncertainty, because many factors such as the fracture risk vary between countries, and thus affect their cost-effectiveness.

The main strengths of this study was gathering cost information from a large sample of patients. In this study, 
cost information was obtained based on medical records of 1150 patients with osteoporosis, wrist, spine, and hip fractures. In contrast, the most important limitation of the current study was the fact that the risk of fractures in the population studied for the 3 strategies was not based on the local information. Although the most reliable previous clinical trials on the risk of fracture were used, the lack of information on drugs' effectiveness in the country was one of the limitations of this study. In general, the 2 previous systematic review studies on the prevalence of osteoporosis in the Iranian women showed that the osteoporosis prevalence in the vertebral and hip was $18.9 \%$ and $17 \%$, respectively $(37,38)$. The results of these studies indicate a high prevalence of osteoporosis in older age groups and in the country's Northern regions, where the osteoporosis rate has been rapidly increasing in the recent years. Thus, the osteoporosis prevalence, especially in menopausal women and in the aging population, combined with this disease, can impose a huge burden on the society and the health system. The results of this study can be useful for the policymakers who aim to make decisions about prioritizing medical interventions for current patients or those at risk of osteoporosis. Moreover, considering the development and the arrival of new interventions and treatments for osteoporosis, it is of utmost importance for the Ministry of Health and other insurance organizations to consider the significance of this issue for the insurance coverage and repayment of the costs of the interventions.

\section{Conclusion}

Over the past 2 decades, economic evaluation studies based on decision analytic models have become an important tool to investigate the cost- effectiveness of medicines used in the prevention and treatment of osteoporosis. This study, which was conducted in the form of a decision tree model, revealed that teriparatide, a recombinant human parathyroid hormone, is not a cost-effective option compared with alendronate and risedronate. The use of teriparatide treatment strategy was more expensive compared with risedronate and alendronate and was associated with a slight increase in QALYs of patients.

Moreover, a significant reduction in the price of teriparatide and restriction in its use only for women at high risk of fracture and for acute and short-term treatment courses can contribute to the cost-effectiveness of the medicine. However, further studies on the local effectiveness of osteoporosis treatment strategies can help enhance the quality of economic evaluation studies in this area.

\section{Conflict of Interests}

The authors declare that they have no competing interests.

\section{References}

1. Genant HK, Cooper C, Poor G, Reid I, Ehrlich G, Kanis J, et al. Interim report and recommendations of the World Health Organization task-force for osteoporosis. Osteoporos Int. 1999;10(4):259-64.

2. Harvey N, Dennison E, Cooper C. Osteoporosis: impact on health and economics. Nat Rev Rheumatol. 2010;6(2):99-105.

3. Vijayakumar R, Büsselberg D. Osteoporosis: An under-recognized public health problem: Local and global risk factors and its regional and worldwide prevalence. Journal of Local and Global Health Science. 2016:2.

4.Hernlund $E$, Svedbom $A$, Ivergård $M$, Compston J, Cooper C, Stenmark J, et al. Osteoporosis in the European Union: medical management, epidemiology and economic burden. Arch Osteoporos. 2013;8(1-2):1-115.

5. Aghaei M, Sedighi S, Pour B, Sh HK, Jamshir M, Agh $A$, et al. Prevalence and risk factors of osteoporosis in postmenopausal women with rheumatoid arthritis: a brief report. Tehran Univ Med J. 2012; 70 (7) :447-51.

6. Zethraeus N, Borgström F, Ström O, Kanis J, Jönsson B. Cost-effectiveness of the treatment and prevention of osteoporosis-a review of the literature and a reference model. Osteoporos Int. 2007;18(1):9-23.

7. Kanis JA, Adams J, Borgström F, Cooper C, Jönsson $B$, Preedy D, et al. The cost-effectiveness of alendronate in the management of osteoporosis. Bone. 2008;42(1):4-15.

8. Burge $\mathrm{R}$, Dawson-Hughes $\mathrm{B}$, Solomon $\mathrm{DH}$, Wong JB, King $A$, Tosteson $A$. Incidence and economic burden of osteoporosis-related fractures in the United States, 2005-2025. J Bone Miner Res. 2007;22(3):465-75.

9. Larijani B, Resch H, Bonjour J, Aghai-Meybodi H, Mohajery-Tehrani M. Osteoporosis in Iran, overview and management. Iran J Public Health. 2007;1:1-13.

10. Larijani B, editor An overview of osteoporosis in Iran. 1st International Osteoporosis Seminar in Iran Teheran, Iran; 2004.

11. Watts NB, Diab DL. Long-term use of bisphosphonates in osteoporosis. J Clin Endocrinol Metab. 2010;95(4):1555-65.

12. Finkelstein JS, Wyland JJ, Lee $H$, Neer RM. Effects of teriparatide, alendronate, or both in women with postmenopausal osteoporosis J Clin Endocrinol Metab. 2010;95(4):1838-45.

13. Liu H, Michaud K, Nayak S, Karpf DB, Owens DK, Garber AM. The cost-effectiveness of therapy with teriparatide and alendronate in women with severe osteoporosis. Arch Intern Med. 2006;166(11):1209-17.

14. Saag KG, Shane E, Boonen S, Marín F, Donley DW, 
Taylor KA, et al. Teriparatide or alendronate in glucocorticoid-induced osteoporosis. N Engl J Med. 2007;357(20):2028-39.

15. Newcomb P, Trentham-Dietz A, Hampton J. Bisphosphonates for osteoporosis treatment are associated with reduced breast cancer risk. $\mathrm{Br} \mathrm{J}$ Cancer. 2010;102(5):799-802.

16. Hiligsmann $M$, Gathon $H J$, Bruyère $O$, Ethgen $O$, Rabenda V, Reginster JY. Cost-effectiveness of osteoporosis screening followed by treatment: the impact of medication adherence. Value Health. 2010;13(4):394-401.

17. Parthan A, Kruse $M$, Yurgin N, Huang J, Viswanathan HN, Taylor D. Cost effectiveness of denosumab versus oral bisphosphonates for postmenopausal osteoporosis in the US. Appl Health Econ Health Policy. 2013;11(5):485-97.

18. Lane NE, Sanchez S, Modin GW, Genant HK, Pierini $E$, Arnaud CD. Parathyroid hormone treatment can reverse corticosteroid-induced osteoporosis. Results of a randomized controlled clinical trial. J Clin Invest. 1998;102(8):1627.

19. Lundkvist J, Johnell O, Cooper C, Sykes D. Economic evaluation of parathyroid hormone (PTH) in the treatment of osteoporosis in postmenopausal women. Osteoporos Int. 2006;17(2):201-11.

20. Macroeconomics $W$. health: Investing in health for economic development. Report of the Commission on Macroeconomics and Health Geneva: World Health Organization. 2001.

21. Mosalanezhad H, Kavosi Z, Keshavarz K, Akrami M, Sarikhani M. Cost-effectiveness of radiotherapy during surgery compared with external radiation therapy in the treatment of women with breast cancer. JHMI. 2016;3(2):33-8.

22. Sorensen O, Crawford G, Mulder H, Hosking D, Gennari C, Mellstrom D, et al. Long-term efficacy of risedronate: a 5-year placebo-controlled clinical experience. Bone. 2003;32(2):120-6.

23. Neer RM, Arnaud $C D$, Zanchetta JR, Prince $R$, Gaich GA, Reginster J-Y, et al. Effect of parathyroid hormone (1-34) on fractures and bone mineral density in postmenopausal women with osteoporosis. N Engl J Med. 2001;344(19):1434-41.

24. Black DM, Cummings SR, Karpf DB, Cauley JA, Thompson DE, Nevitt MC, et al. Randomised trial of effect of alendronate on risk of fracture in women with existing vertebral fractures. The Lancet. 1996;348(9041):1535-41.

25. Congress U. Hip fracture outcomes in people age
50 and over. Background paper Government Printing Office, Washington, DC, USA. 1994.

26. Hiligsmann $M$, Evers $S M$, Sedrine $W B$, Kanis JA, Ramaekers $B$, Reginster J-Y, et al. A systematic review of cost-effectiveness analyses of drugs for postmenopausal osteoporosis. Pharmacoeconomics. 2015;33(3):205-24.

27. Murphy DR, Smolen LJ, Klein TM, Klein RW. The cost effectiveness of teriparatide as a first-line treatment for glucocorticoid-induced and postmenopausal osteoporosis patients in Sweden. BMC Musculoskelet Disord. 2012;13(1):1.

28. Borgström F, Ström O, Marin F, Kutahov A, Ljunggren Ö. Cost effectiveness of teriparatide and PTH (1-84) in the treatment of postmenopausal osteoporosis. J Med Econ. 2010;13(3):381-92.

29. Lippuner K, Johansson H, Borgström F, Kanis J, Rizzoli R. Cost-effective intervention thresholds against osteoporotic fractures based on FRAX ${ }^{\circledR}$ in Switzerland. Osteoporos Int. 2012;23(11):2579-89.

30. Hiligsmann M, Rabenda V, Gathon H-J, Ethgen O, Reginster J-Y. Potential clinical and economic impact of nonadherence with osteoporosis medications. Calcif Tissue Int. 2010;86(3):202-10.

31. Wasserfallen J-B, Krieg M-A, Greiner R-A, Lamy $O$. Cost effectiveness and cost utility of risedronate for osteoporosis treatment and fracture prevention in women: a Swiss perspective. J Med Econ. 2008;11(3):499-523.

32. Borgström $F$, Ström $O$, Coelho J, Johansson $H$, Odén A, McCloskey $E$, et al. The cost-effectiveness of risedronate in the UK for the management of osteoporosis using the $\mathrm{FRAX}^{\circledR}$. Osteoporos Int. 2010;21(3):495-505.

33. Fleurence RL, Iglesias CP, Johnson JM. The cost effectiveness of bisphosphonates for the prevention and treatment of osteoporosis. Pharmacoeconomics. 2007;25(11):913-33.

34. National Institute for Health and Clinical Excellence. Alendronate, Etidronate, Risedronate, Raloxifene, Strontium Ranelate and Teriparatide for the Secondary Prevention of Osteoporotic Fragility Fractures in Postmenopausal Women: National Institute for Health and Clinical Excellence; 2008.

35. Thompson M, Pasquale M, Grima D, Moehrke W, Kruse HP. The Impact of Fewer Hip Fractures with Risedronate Versus Alendronate in the First Year of Treatment: Modeled German Cost-Effectiveness Analysis. Value Health. 2010;13(1):46-54.

36. Tosteson A, Burge RT, Marshall DA, Lindsay R. 
Therapies for treatment of osteoporosis in US women: cost-effectiveness and budget impact considerations. Am J Manag Care. 2008;14(9):605-

15.

37. Irani AD, Poorolajal J, Khalilian A, Esmailnasab N, Cheraghi Z. Prevalence of osteoporosis in Iran: A meta-analysis. J Res Med Sci. 2013;18(9):759-66.

38. bagheri $p$, haghdoost aa, dortaj rabari e, halimi I, vafaei $z$, farhang nya $m$, et al. Ultra Analysis of Prevalence of Osteoporosis in Iranian Women:A Systematic Review and Meta-analysis. IJEM. 2011;13(3):315-25 